\title{
EXPLORING BARRIERS TO REPRODUCTIVE HEALTH SERVICES UTILIZATION AMONG YOUTH, AQUALITATIVE STUDY IN DISTRICT RAWALPINDI, PUNJAB, PAKISTAN
}

\author{
Shakila Bangash ${ }^{1}$, Saima Hamid $^{2}$ and Nasreen Hassan Niazi ${ }^{3}$ \\ ${ }^{1}$ Fellow Health Services Academy Quaid e Azam University, Islamabad, Pakistan \\ ${ }^{2}$ Registrar/Associate professor, Health Services Academy, Islamabad \\ ${ }^{3}$ Gynecologist $\mathrm{CMH}$, Muzaferabad. \\ Correspondence: Shakila Bangash. Email: drshakilabangash980@gmail.com
}

\begin{abstract}
Background: Reproductive health services are vital to health and survival of young women. Pakistan has $35 \%$ of young population and according to PDHS $48 \%$ births takes place in health facility in which only $15 \%$ in public facility and $52 \%$ takes place at home. Youth faces barriers to utilization are related to accessibility, acceptability, how appropriate the services are and equity of reproductive health services.

Methods: Cross sectional Qualitative method was used. Quantitative part of study consisted of 130 females of 15 24 years of age and qualitative part comprised of five in depth interviews with HCP including Doctors and Nursing staff from five clinics providing reproductive health services in BBH, Rawalpindi, Punjab..

Results: The barriers that HCP considered were married women centered reproductive health services, no separate place for youth, timings were not convenient to youth, and cultural context was barrier to confidentiality. The factors youth consider to be hindering utilization of health services were behavior of health care provider, treatment of reception and support staff, cost of health services, knowledge regarding available services, confidentiality, interruptions during service delivery, lack of privacy as the $p$ value is less than 0.05

Conclusion: For enhancing the utilization of reproductive health services in public facility by youth these barriers needs to be addressed at policy level and at health system level.
\end{abstract}

Keywords: Youth, utilization, youth friendly health services, reproductive health services, mixed method study

\section{Introduction}

Young people makes 1.8 billion of the world population between the age of $10-24$ and $89 \%$ of youth are living in less developing countries. Today $3 / 5$ of maternal deaths occurs in countries where health systems are fragile due to conflict or disasters. Pakistan with $35 \%$ of youth of the total population makes up 59 million (1). In 1994, the international Conference on Population and development program of Action called upon making the availability of youth specific reproductive health services including information and counseling to prevent early marriages and high risk childbearing to reduce related mortality (2). Some of the barriers that youth face in obtaining these services relate to availability, accessibility, acceptability and equity of health service (3). The National Health Policy 2001 following ICPD agenda has included Adolescent health issues in spite an enormous deal of stress is on raising the knowledge about safe motherhood, the health of new born, family planning to eligible couples and increasing number of skilled human resource via LHW deployment (4). A quantitative study conducted in Nepal reported socio- culture barriers to antenatal services utilization (5). The study done in urban and rural settings in Pakistan where non availability of health care provided was found to a barrier to utilization (6). In 2016 researchers concluded that barriers affecting the utilization of antenatal care services in rural areas were social, financial limitations and community mid wives non acceptability (7). Barriers to Low utilization of maternal and child health services were low awareness among community, lengthy distances, cost of health services, and poor functional services (8). A study in government health facilities of Nepal revealed education, economic status, dissatisfaction with the health services, the information provided during ANC visit, unreceptive attitude of health worker as major hindering factors associated with antenatal visits dropouts (9).

Hitherto, different factors related to reproductive health still needs to explore in study area due to multicultural society. This study has explored the barriers to reproductive health services utilization in Tertiary care hospital from the perspective of youth and health care providers and to elicit solution to these barriers thereby 
increasing reproductive health services utilization in public hospital.

\section{Methodology}

A Qualitative study design was employed from June to August 2016.The study was conducted in Benazir Bhutto Hospital of Rawalpindi district. Rawalpindi district covers the area of $5285 \mathrm{Sq} . \mathrm{Kms}$ with a population of 33, 63911 persons. Male are $51 \%$ and female are $49 \%$ of total population with age structure of 15 to 24 years is $21.5 \%$ and with CPR of $41.5 \%$ (10). Andersen and Newman model of service utilization was adapted to guide the study (13). This model describes healthcare utilization as a function of factors predisposing to and enabling utilization, and factors that determine people's need for healthcare services. This study examined the predisposing and enabling factors hindering the reproductive health services utilization. Purposive sampling of young married and unmarried women of age 15 -24 years from five clinics and five health care providers in each clinic were adopted. Total 260 sample size required for client survey is calculated as below by sample size equation for population proportion and Quota sampling was done with stratification in to male and female and equal allocation of 130 males and 130 female's clients for survey. Both the data collection instruments were adapted from World Health Organization (12). Client exit questionnaire and in depth interview guide were composed in Urdu. The pretested questionnaire was edited by Clinical Psychologist serving in Adolescent clinic and translated and composed in Urdu, the local language. Survey Questionnaire and interview guide were pretested before data collection. Survey Questionnaire was pretested in PIMS with 13 young 15 -24years clients' i-e $10 \%$ of the sample size. Interview guide was pretested with 2 health care providers before actual data collection at PIMS Interview guide was also translated and composed in Urdu, the local language. Before finalizing the data collection tool recommended changes were included. Client survey analysis was done by using SPPS software. For analysis of qualitative data Inductive Content analysis was done. By definition qualitative content analysis is a research method to subjectively interpret the content of collected text data through process of classifying codes and emerging sub themes and themes (13). The ethical consideration has been taken from Health Services Academy, Director of population Welfare Department, Rawalpindi and Medical superintended of Benazir Bhutto Hospital, Rawalpindi. Verbal consent has been taken from married participants and written consent from young unmarried participants and their guardians.

\section{Results}

The survey included 130 females. Majority of the participants were between 21-24 years age from urban area and were married. Most of the participants were primary level of education and no schooling and were unemployed (Table 1).
Table 1: Demographic Characteristic of Participants

\begin{tabular}{|c|c|c|}
\hline \multicolumn{2}{|c|}{ Variables $(n=130)$} & \multirow{2}{*}{$\begin{array}{l}\text { Frequency (\%) } \\
45(43.6 \%)\end{array}$} \\
\hline \multirow[b]{2}{*}{ Age } & $15-20$ & \\
\hline & $21-24$ & $85(64.3 \%)$ \\
\hline \multirow[t]{2}{*}{ Residence } & Urban & $74(56.9 \%)$ \\
\hline & Rural & $56(43.1 \%)$ \\
\hline \multirow[t]{2}{*}{ Marital Status } & Unmarried & $21(16.2 \%)$ \\
\hline & Married & $109(83.8 \%)$ \\
\hline \multirow[t]{4}{*}{ Education } & No Schooling & $34(26.2 \%)$ \\
\hline & Primary & $38(29.2 \%)$ \\
\hline & Secondary & $54(41.5 \%)$ \\
\hline & University & $4(3.1 \%)$ \\
\hline \multicolumn{3}{|l|}{ Employment } \\
\hline \multirow[t]{2}{*}{ Status } & Yes & $16(12.3 \%)$ \\
\hline & No & $114(87.7 \%)$ \\
\hline
\end{tabular}

Data obtained from five in depth interviews with health care providers was analyzed by content analysis. Audio recordings were transcribed verbatim in Urdu language and then in to English. Principal researcher did coding. The main theme and subthemes identified are given below

\section{Married women centered Reproductive health services}

All health care providers were not aware of the term YFHS. They all knew that services to youth needs provision according to their needs Health care providers were not aware of YFHS characteristics but they knew that their clinics were youth friendly as they provided services to all age groups without any discrimination.

One of the respondents said

Trying to make it Youth Friendly but not yet succeeded. We provide services to youth both married and unmarried and to both males and females. As far male clients are concern we get very few male of younger age group. Male clients are mostly above 35 years and those of 40 45years coming for vasectomy (In charge $F H C+A H C, P W D)$

Another said

"Yes, because we provide equal services to all age group but these services are part of integrated reproductive health services and not a separate youth oriented center" (. Doctor MBBS Post Graduate Trainee)

"Yes, because we receive majority of young clients, young girls married in antenatal clinics and in our gynae department we receive clients of 15-20 years but they receive integrated services as no separate clinic is yet established. Young unmarried client's ratio is low as 
compare to married clients" (Post Graduate Trainee at Emergency Department(ER) Gynecology)

The subthemes are given hereunder

\section{a) No policy restriction and services are provided without discrimination}

Health care providers were agreed that their clinics have no such policy to restrict the provision of health care services to youth. They provide services to all age group without any differences but these services are female centered services and they are provided as part of integrated services..Health care providers reported no discriminatory behavior towards young clients and that they treat every client with care and respect.

"No, we do not have such policies. All the clients coming in our clinic are provided the required services. All are entertained equally".( Doctor MBBS Post Graduate Trainee Gynecology)

\section{b) Youth hesitate to come}

Health care providers from PWD (Population Welfare Department) added that they have separate center for youth and they had been working for more than a year but most of clients they received are referred from other departments and Family Health Centre for counseling. They added that mostly youth come for services are married and unmarried clients are few.

"No, our clinic has no such policy to prevent youth from getting services but people hesitate coming here because this centre is consider Family Planning Centre and young people come less frequent".(In charge of Population Welfare Department, BBH, Rawalpindi)

\section{c) Behavior of support staff}

All the responded agreed that the support staff is not friendly and their dealings with clients is disrespectful. Health care providers reported bad behavior of support staff at reception and of the cleaning staff. Health care providers reported that the staff at reception often misbehaves with client's relatives. They all agreed that reception staff lacks the training in managing the client burden. They agreed that most staff was absent from their duties.

" Staff at reception is often absent and they cannot manage the crowded clients and they are so busy that they are unable to guide the patient properly. Clients at reception waiting for their turn early morning as they came from far areas but the reception counter is opened late and they tried to get the slip early"(Doctor MBBS Post Graduate Trainee Gynecology)

\section{Affordable but timings are not feasible to youth}

All the health care providers were agreed that in public hospital only fee of consultation slip is paid by the clients. All the services in the outpatient department are affordable but for the admitted clients and those undergoing some surgical procedures clients had to pay. a) Services free of cost

The services provided at PWD were free of cost. Respondent from this clinic expressed that they are providing free services to all age groups but they receive only few young clients. Health care providers admitted that they do not charge for the surgical procedures and family planning products. They added that clients can receive free these services in community also

"We have policies and we provide free services and family planning products but clients came for family planning is above 25 years. They are provide consultation services and surgical procedures are done free of cost. So we can say that cost is not an issue"(In charge $\mathrm{FHC}+\mathrm{AHC}, \mathrm{PWD})$

Illiteracy poses a barrier to confidentiality

Respondents agreed that their department had specific policy to keep the client illness and medical record confidential but as most of the clients especially those unmarried young clients who are less educated or illiterate, their guardian or relatives needed to be involved

Said one of respondents

"Confidentiality is certainly guaranteed. The information is shared only with the patient and their guardian and attendant."(Post Graduate Trainee, Gynecology obstetrics department BBH)

\section{Lack of age appropriate RH services}

Health care providers from PWD (Population Welfare Department) admitted that the services provided at their clinic did not cater all reproductive health issues of youth. At Family Health center only family planning services are provided to eligible couples along with adult clients and for antenatal, postnatal they had to refer the clients to hospital. Adolescent center had only counseling service for youth and other services were not provided.

One of respondents said

"Counseling is provided regarding family planning choices to married youth and we also receive young girls with reproductive health issues and if they are in need of medical or surgical opinion we send them to concern department in the hospital. Young girls come with pubertal issues, skin problems but we cannot advise some treatment without expert opinion". (In charge PWD, Population Welfare Department)

\section{Discussion}

The results of study shows that females of younger age group i-e 15 -20 utilized the reproductive health services less as compare to older group. Females' service utilization from urban region is high as compare to rural. The more the youth is educated the less is utilization of services from public hospital This finding are in consistent with the National Demographic Health Survey which showed that the level of education, place of residence and occupation are the factors related to utilization of reproductive health services among married women of reproductive age. Young mothers avail services from skilled health provider for first birth than older ones but there is decline with increasing number of pregnancies. In Punjab utilization of reproductive health services is greater in urban as 
compare to rural population. Education wise service utilization in public sector is low as compare to private sector (5). Analytical statistics shows association of education with utilization of health services and this finding is also agreed in systematic analysis of behavioral model of health service utilization (13). The association between patients satisfaction with health services and socio-demographic factors has been concluded in quantitative study conducted in Nepal in 2015. They reported that socio-culture barriers to antenatal services utilization needs to be addressed (8). Similar findings related to utilization of antenatal services from Ethiopia were reported (14). Non use of health services was significantly related to wealth status, educational attainment, residence, geographical locations, age and marital status of the respondents (15). Providers related barriers are poor knowledge of health care providers regarding youth friendly services. Most of the providers had poor perceptions of youth friendliness of health services. Similar findings were reported from the systematic review of indicators drawn from perspectives of youth (16). Behavior of health care providers, receptionists and the support staff has been identified by youth and this corresponds with research study done in Vanuatu (17). Health care providers reported that lack of staff and absentees of staff found to be related to non friendly behavior to youth. The finding is similar as found in South Africa where lack of youth-friendly training among staff and lack of a dedicated space for young people was found to be a barrier faced by youth (18).

The study conducted in 2013 revealed similar findings by stressing upon the interpersonal relations formed a barrier young people access to and satisfaction of health services (19). Negative attitudes of health workers were to be posing barriers to unmarried adolescent service utilization (20). Association was found between satisfaction of pregnant women with attitude of health care provider in public and private antenatal clinics (21). The factors operate at health service delivery level are non availability of separate provision of reproductive health to youths, costs of health services, overcrowded hospital, Timings of health services delivery, Shortage of medicines, Interruptions during service delivery The findings are similar as in previous studies (22).

\section{Conclusion}

The study concluded that reproductive health service provision in public hospital is not according to the needs of young people and has failed to provide appropriate services to them. Behavior of health care provider and related staff is most crucial concern among youth.

\section{References}

1 Gupta MD, Engelman R, Levy J, Luchsinger G, Merrick T, Rosen JE. The Power of 1.8 billion State of world population. 2014:136.

2 Lince-Deroche N, Hargey A, Holt K, Shochet T. Accessing Sexual and Reproductive Health
Information and Services: A Mixed Methods Study of Young Women's Needs and Experiences in Soweto, South Africa. African journal of reproductive health. 2015 Mar 1;19(1):73-81.

3 Deo KK, Paudel YR, Khatri RB, Bhaskar RK, Paudel R, Mehata S, Wagle RR. Barriers to Utilization of Antenatal Care Services in Eastern Nepal. Frontiers in public health. 2015;3.

4 Nisar YB, Aurangzeb B, Dibley MJ, Alam A. Qualitative exploration of facilitating factors and barriers to use of antenatal care services by pregnant women in urban and rural settings in Pakistan. BMC pregnancy and childbirth. 2016 Mar 1;16(1):1.

5 Sarfraz M, Tariq S, Hamid S, Iqbal N. social and societal barriers in utilization of maternal health care services in rural punjab, pakistan. Journal of Ayub Medical College Abbottabad. 2016 Jan 6;27(4):843.

6 Memon Z, Zaidi S, Riaz A. Residual Barriers for Utilization of Maternal and Child Health Services: Community Perceptions From Rural Pakistan. Global journal of health science. 2016 Jul;8(7):47.

7 Singh DR, Jha T. Exploring Factors Influencing Antenatal Care Visit Dropout at Government Health Facilities of Dhanusha District, Nepal. American Journal of Public Health Research. 2016 Aug 27;4(5):170-5.

8 Babitsch B, Gohl D, von Lengerke T. Rerevisiting Andersen's Behavioral Model of Health Services Use: a systematic review of studies from 1998-2011. GMS Psychosoc Med. 2012; 9: Doc11. doi: 10.3205/psm000089.

9 Hsieh, H.-F. and S. E. Shannon (2005). "Three approaches to qualitative content analysis." Qualitative health research15 (9): 1277-1288.

10 Birmeta K, Dibaba Y, Woldeyohannes D. Determinants of maternal health care utilization in Holeta town, central Ethiopia. BMC health services research. 2013 Jul 3;13(1):1.

11 Alli F, Maharaj P, Vawda MY. Interpersonal relations between health care workers and young clients: barriers to accessing sexual and reproductive health care. Journal of community health. 2013 Feb 1;38(1):150-5

12 Ambresin A-E, Bennett K, Patton GC, Sanci LA, Sawyer SM. Assessment of youth-friendly health care: a systematic review of indicators drawn from young people's perspectives. Journal of Adolescent Health. 2013;52(6):67081

13 Kennedy EC, Bulu S, Harris J, Humphreys D, Malverus J, Gray NJ. "Be kind to young people so they feel at home": a qualitative study of adolescents' and service providers' perceptions of youth-friendly sexual and reproductive health 
services in Vanuatu. BMC health services research. 2013;13(1):455

14 Geary RS, Gómez-Olivé FX, Kahn K, Tollman S, Norris SA. Barriers to and facilitators of the provision of a youth-friendly health services programme in rural South Africa. BMC health services research. 2014;14(1):259.

15 Tilahun M, Mengistie B, Egata G, Reda AA. Health workers' attitudes toward sexual and reproductive health services for unmarried adolescents in Ethiopia. Reproductive health. 2012 Sep 3;9(1):1.

16 Tangmunkongvorakul A, Banwell C, Carmichael G, Utomo ID, Seubsman SA, Kelly M, Sleigh A. use and perceptions of sexual and reproductive health services among young northern thai people. The Southeast Asian journal of tropical medicine and public health. 2012 Mar;43(2):479.

17 ZA Z. Satisfaction among pregnant women towards antenatal care in public and private care clinics in Khartoum. Khartoum Medical Journal. 2012 Jan 7;4(2).

18 Nisar YB, Aurangzeb B, Dibley MJ, Alam A. Qualitative exploration of facilitating factors and barriers to use of antenatal care services by pregnant women in urban and rural settings in Pakistan. BMC pregnancy and childbirth. 2016 Mar 1;16(1):1.

19 Rahmani Z, Brekke M. Antenatal and obstetric care in Afghanistan-a qualitative study among health care receivers and health care providers. BMC health services research. 2013 May 6;13(1):1.

20 Adeyemo FO, Amiegheme FE, Enuku CA, Okpala PU. Utilization of health services for reproductive health problems among the undergraduates in Ogbomoso. Asian Journal of Nursing Education and Research. 2013 Apr $1 ; 3(2): 1$.

21 Ganle JK, Parker M, Fitzpatrick R, Otupiri E. A qualitative study of health system barriers to accessibility and utilization of maternal and newborn healthcare services in Ghana after user-fee abolition. BMC pregnancy and childbirth. 2014 Dec 21;14(1):1

22 .Mannava P, Durrant K, Fisher J, Chersich M, Luchters S. Attitudes and behaviours of maternal health care providers in interactions with clients: a systematic review. Globalization and health. 2015Aug 15;11(1):36. 